\title{
Sodium and Potassium Intakes assessed by 24-h Urine among Moroccan University students in Casablanca, Morocco: Cross-Sectional Study
}

\author{
Maria Elarbaoui ${ }^{1 *}$, Ali Jafri ${ }^{2}$, Younes Elkardi ${ }^{1}$, Houria Makhlouki ${ }^{1}$, BasmaEllahi ${ }^{3}$, \\ andAbdelfettahDerouiche ${ }^{1}$.
}

\begin{abstract}
${ }^{1}$ Laboratory of Biology and Health, Research Unit: Human Nutrition, URAC 34, Faculty of sciences Ben Msik, Hassan II University of Casablanca, Morocco, Avenue CdtDriss El Harti, B.P 7955, SidiOthmane, Casablanca /20660, Morocco.

${ }^{2}$ Mohammed VI University of Health Sciences, Faculty of Medecine, UM6SS, Morocco, BldmohammedTaiebNaciri, Commune Hay Hassani /82 403, Anfa City, Casablanca, Morocco.

${ }^{3}$ Faculty of Health and Social, Chester University, Chester, United Kingdom, Parkgate Road,Chester/ CH1 4BJ, United Kingdom.
\end{abstract}

\begin{abstract}
In Morocco, the high consumption of dietary sodium increases the risk of non-communicable diseases (NCDs) and predisposes to cardiovascular diseases (CVDs) and hypertension. This study aims to assess the dietary sodium and potassium intake in a random sample of Moroccan adult students as a benchmark informing a national strategy for reducing salt intake. This cross-sectional study was conducted with 103 adults aged 18 to 25 years recruited in Casablanca. The 24-hour urinary excretion was used to measure the sodium and potassium. Creatinine excretion was used to validate the completeness of the urine collections. The average urinary sodium excretion was $3125.77 \pm 121.99 \mathrm{mg} /$ day, $13.5 \%$ consumed less than $5 \mathrm{~g} /$ day, while $69 \%$ consumed more than $5 \mathrm{~g}$ /day of which $17.5 \%$ consumed more than twice the recommendations. For the average urinary potassium excretion was $1826.1 \pm 61.2 \mathrm{mg} /$ day, and more than $98 \%$ of the students consumed less than the adequate intake. The results of this pilot study show that the population studied has a high sodium intake and low potassium intake which does not meet World Health Organization (WHO) recommendations, which requires implementing an action plan to reduce salt.
\end{abstract}

\section{Introduction}

Globally, NCDs are the leading cause of death and morbidity accounting for $71 \%$ of deaths, the equivalent of 41 million deaths per year according to the WHO [1]. CVDs are responsible for the largest number of deaths from non communicable diseases (17.9 million per year), of which high blood pressure (hypertension) is a major risk factor [2]. One of the main causes of the latter is high sodium intake. However, high potassium consumption can counteract the negative effects of high sodium intake on blood pressure. Potassium therefore plays a protective role, in lowering blood pressure [3]. WHOs report highlights the importance of prioritizing the reduction of sodium intake as the primary approach to reducing blood pressure and reducing the risk of stroke and CVDs [4].

* Corresponding author:afderoucihe@email.com 
On the other hand, eating behaviors have changed significantly in the past three decades, resulting in an overconsumption of fatty, salty and sweet foods across the world both in developed and developing countries [5]. The rising number of NCDs such as CVDs and hypertension has been attributed to these nutritional changes. Globally, $22 \%$ of the adult population aged 18 and over are hypertensive. More specifically, in Morocco hypertension is a public health problem. Indeed, data from the latest study concluded that $29.3 \%$ of Moroccans aged 18 and over have high blood pressure. Furthermore, the latest results of the Ministry of Health prospective survey show that the prevalence of hypertension decreased from $33.6 \%$ in 2000 to $29.3 \%$ in 2017 . Efforts will be made to achieve a $10 \%$ reduction in the prevalence of hypertension by 2029 [6].

In this context, we assess the consumption of sodium and potassium. The intake of these micronutrients can be estimated indirectly from a questionnaire, or directly by measuring urinary excretion. Due to problems of sodium inaccuracy based on dietary studies in most researches, twenty-four hours urinary sodium excretion has become the "gold standard" method of obtaining sodium and potassium intake[8].

In Morocco, available data revealed that sodium and potassium intake verified by $24-\mathrm{h}$ urine collection in children between 6 and 18 of age is respectively $2235.3 \pm 823.2 \mathrm{mg} /$ day $2.2 \pm 0.8 \mathrm{~g} /$ day and $1431 \pm 636.5 \mathrm{mg} /$ day [9], and in adults aged 25 to 65 years are respectively $2838.7 \pm 1442.5 \mathrm{mg} /$ day $2.8 \pm 1.4 \mathrm{~g} /$ day and $1377.3 \pm 642.4 \mathrm{mg} /$ day [10]. However, the daily intake of sodium and potassium through the diet of young people aged 18 to 25 years remains unknown.

The present study set out to assess the mean daily intakes of sodium and potassium in Moroccan university students aged 18 to 25 years living in the Casablanca region in westcentral Morocco, with the aim (as a pilot study) of informing the national strategy to reduce salt intake.

\section{Methods}

To collect data on health problems, date of birth and drug consumption and/or supplements, we conducted an anthropometric measurement, urine collection and face-to-face interviews with students from 18 to 25 years enrolled at the Hassan II University of Casablanca. This cross-sectional study was carried out between December 2017 and March 2018. Individual information from participants was collected using a standard WHO-EMRO (the Eastern Mediterranean Regional Office) questionnaire. 24-hour urine samples were collected. Participants were given detailed instructions on timed urine collection during the 24 hours to estimate excretion. As requested, the first urine of the day was discarded to start the urine collection period with an empty bladder, 5-liter of boric acid, which was used for preservation of urine before chemical analyses where bacterial metabolism is likely to invalidate the results [11]. Anthropometric measurements reflect nutritional and health status but can also be used to predict health status and survival [14]. They were taken in the university, according to WHO recommendations, and collected by trained researchers in accordance with WHO standards [15]. The total volume of urine collected was measured using a specially designed linear measurement scale, and an aliquot $(30 \mathrm{ml})$ of the complete samples was stored at the $-20^{\circ} \mathrm{C}$ until analysis. Analysis of sodium, potassium and creatinine levels in the urine was carried out using potentiometric and colorimetric methods (PLC Fusion 5.1 technique, Ortho Clinical Diagnostics VITROS from Johnson and Johnson USA); this technique makes it possible to measure sodium and potassium ions by direct potentiometry. 
Blood pressure was measured using an Omron M6 blood pressure monitor [18], measurements were completed in the sitting position after 5 minutes of rest prior the measurements. All Statistical analysis were carried out using SPSS Statistics software (IBM SPSS Statistics 25.0) [19].

\section{Results:}

This study provides an estimation of the sodium and potassium intakes of Moroccan students by measuring the urinary excretion of sodium and potassium for 24 hours.

In our study, men represent $47.6 \%$ (49) and women $52.4 \%$ (54). The average age of participants was $21.6 \pm 0.1$ years, of which $21.8 \pm 0.3$ years for men and $21.4 \pm 0.1$ years for women. The characteristics of growth parameters for all participants are presented in Table1. For overall recruited students, the mean weight was $64.8 \pm 1.3 \mathrm{~kg}$ and the average height was $168.7 \pm 0.9 \mathrm{~cm}$. The average urinary sodium excretion of 24 hours in the whole group was $3.1 \pm 0.1 \mathrm{~g}$ /day (equivalent to $7.8 \pm 0.3 \mathrm{~g}$ /day of salt). Overall, $13.6 \%$ of students have a sodium excretion below $2000 \mathrm{mg}, 8.16 \%$ men and $18.52 \%$ women consuming less than $5 \mathrm{~g} /$ day, which corresponds to the recommendations of the WHO. While $68.9 \%$ ( $67.4 \%$ men and 70.4\% women) have an excretion between 2 and $4 \mathrm{~g}$ (consume between 5 $10 \mathrm{~g}$ of salt per day), and $17.5 \%$ exceed $4000 \mathrm{mg}$ per day, which $24.5 \%$ men and $11.11 \%$ women consume more than twice the recommendations.

The average urinary potassium excretion of 24 hours in the whole group was $1826.1 \pm 61.2$ $\mathrm{mg} /$ day, and more than $98 \%$ of students consumed less than adequate intake, and only one person in the entire population has a value greater than $3500 \mathrm{mg} / \mathrm{day}$.

A comparison of daily urinary excretion of potassium, sodium and creatinine between men and women is also reported in Table 1, and showed significant difference between women and men for sodium, potassium and creatinine $(p=0.0321, p=0.0201$ and $p<0.0001$ respectively), and no significant statistical difference for urine, SBP and DBP ( $p=0.2047$, $\mathrm{p}=0.984$ and $\mathrm{p}=0.392$ respectively).

For nutritional status, the BMI indicate that $13.6 \%$ of students are underweight, $63.1 \%$ normal weight, $18.4 \%$ are overweight and $4.9 \%$ are obese. Potassium was low in all groups regardless of weight status (i.e. not significantly different) whereas sodium was lower in the underweight group than the others. The overweight group appeared to have lower sodium excretion than the obese or normal weight groups.

No significant correlation was observed between sodium and arterial pressure (TAS; $r=$ $0.075, \mathrm{p}=0.449$ and TAD; $\mathrm{r}=0.052, \mathrm{p}=0.599)$. However, BMI does not show any significant correlation between $\mathrm{K}$ and $\mathrm{Na}(\mathrm{p} \geq 0.05)$. A significant positive correlation was observed between weight, potassium and sodium $(\mathrm{r}=0.26, \mathrm{p}=0.008$ and $\mathrm{p}=0.007$ respectively),

In contrast, no significant negative correlation were observed between the sodium/potassium intake ratio and arterial pressure (TAS; $r=-0.038, \mathrm{P}=0.702$ and TAD; $\mathrm{r}$ $=-0.18, \mathrm{P}=0.859)$. 


\section{Discussion}

In this study, the assessment of sodium and potassium intake in university students, clearly showed that sodium consumption exceeds the recommended values With 24-hour urinary sodium excretion, the mean sodium concentration was $3.1 \pm 0.1 \mathrm{~g} /$ day (equivalent to $7.8 \pm$ $0.3 \mathrm{~g} /$ day of salt; $7.2 \mathrm{~g}$ in women and $8.5 \mathrm{~g}$ in men).

Our results are in agreement with a study carried out in South Africa, the average salt consumption estimated by the 24-hour urinary excretion method was $7.2 \mathrm{~g} /$ day and $65.6 \%$ consumed more than $6 \mathrm{~g}$ of salt/d [25]. Similarly, in USA an adult population aged 18-25 years showed that sodium consumption was $3.5 \mathrm{~g}$ /day equivalent to $8.6 \mathrm{~g} /$ day of salt [26]. On the other hand, potassium is known to be a key mediator of the cardiovascular effect on food sodium, it is proven that a diet rich in potassium has a vasculo-protective function, especially in cases of hypertension sensitive to salt and pre-hypertension [27]. A low intake of this element is associated with hypertension since it presents a protective factor for hypertensive people [28]. As well as the increase in potassium intake reduces the hypertensive response following a sodium-rich intake [27].

These results are in agreement with work carried out in three different South African populations. The study showed that the usual median intakes of potassium of university Students was $1309,85 \mathrm{mg} /$ day, which is lower than recommended values [28].

Low potassium intake maybe associated with insufficient intake of fruits and vegetables, but also by certain traditional cooking techniques, namely that potassium is watersoluble[32]. To prevent it from escaping into the cooking water, it is preferable to cook the food with steam, in a foil or stew.

Furthermore, the high sodium intake results can be related to the high prevalence of hypertension in Morocco and/or by traditional eating habits and practices using very salty seasonings and condiments [25]. Bread is one of the most important sources of sodium in several countries, and also the main vehicle of salt for daily food intake in Morocco [29]. Indeed, most bakeries use between 15 and $20 \mathrm{~g}$ of salt $/ \mathrm{kg}$ in bread preparation and in diet. However, the Moroccans are large consumers of bread during meals, with an average of $500 \mathrm{~g} /$ day/person, which leads to a daily intake of 8 to $9 \mathrm{~g}$ of salt through bread alone[30].

This study highlights that sodium is over-consumed compared to a low potassium consumption $(3.1 \pm 0.1 \mathrm{~g} /$ day $-1826.1 \pm 61.2 \mathrm{mg} /$ day respectively). According to the Examination of Moroccan national survey data. Morocco has registered a nutritional transition [40]. Indeed, the diet changed considerably; the intake of animal products increased while that of cereals and sugar remained relatively high. The rise in the consumption of meats and vegetables was accompanied by a steady consumption of bread, used to eat the sauce in which the meat and vegetables are cooked; processed foods and fast food have been dramatically increased.

The high sodium and inadequate potassium status in our sample could be explained by the change in eating behavior, in fact Morocco has recorded a nutritional transition, leading to changes in eating habits and lifestyle changes, especially in the largest cities like the Casablanca, region resulting from increased consumption of processed foods and fast food [31].

Several epidemiological reports have shown a relationship between sodium and potassium intake, cardiovascular disease and mortality in the general population [32]. The excess in sodium intake and potassium deficiency in Morocco reflects the world situation. Because of this worrying situation, WHO has developed and implemented a global strategy and effective policies to reduce salt intake. 


\section{Conclusion}

Our pilot study shows that sodium and potassium intake, estimated by 24-hour urinary excretion, was (on average) different from WHO recommendations. This could contribute to the high risk of developing hypertension, cardiovascular disease and stroke. Therefore, it is urgent to take measures to reduce sodium consumption; in this way, more research is needed in this area.

\section{References}

1. W. H. Organization, « Noncommunicable diseases country profiles 2018 », 2018.

2. A. Perrine, C. Lecoffre, J. Blacher, et V. Olié, «L'hypertension artérielle en France: prévalence, traitement et contrôle en 2015 et évolution depuis 2006 », Rev. Biol. MédicaleN, vol. 347, no 76, 2019.

3. Y. El Achhab, L. Nazek, M. Maalej, M. Alami, et C. Nejjari, «Prevalence, control and risk factors related to hypertension among Moroccan adults: a multicentre study », East. Mediterr. Health J., vol. 25, no 7, p. 447 $\square 456,2019$.

4. W. H. Organization, « Global strategy on diet, physical activity and health », 2004.

5. J. Kearney, «Food consumption trends and drivers », Philos. Trans. R. Soc. B Biol. Sci., vol. 365, no 1554, p. $2793 \square 2807,2010$.

6. M. Benghanem Gharbi et al., "Chronic kidney disease, hypertension, diabetes, and obesity in the adult population of Morocco: how to avoid "over"- and "under"diagnosis of CKD », Kidney Int., vol. 89, no 6, p. 1363 $\square 1371$, juin 2016, doi: 10.1016/j.kint.2016.02.019.

7. «STEPS-REPORT-2017-2018-Morocco-final.pdf». Consulté le: janv. 15, 2021. [En ligne]. Disponible sur: https://www.who.int/ncds/surveillance/steps/STEPS-REPORT2017-2018-Morocco-final.pdf

8. F. J. He, M. Tan, Y. Ma, et G. A. MacGregor, «Salt Reduction to Prevent Hypertension and Cardiovascular Disease: JACC State-of-the-Art Review », J. Am. Coll. Cardiol., vol. 75, no 6, p. 632 $\square 647,2020$.

9. R. M. McLean, «Measuring population sodium intake: a review of methods », Nutrients, vol. 6, no 11, p. 4651 $\square 4662,2014$.

10. N. Saeid et al., " Assessment of sodium and potassium intakes in children aged 6 to 18 years by 24 h urinary excretion in city of rabat, Morocco », J. Nutr. Metab., vol. 2018, 2018.

11. A. Derouiche, Y. El-Kardi, K. Mohtadi, et A. Jafri, «Salt intake assessed by 24 hour urinary sodium excretion of Moroccan adults: A pilot study », Nutr. Clin. Métabolisme, vol. 31, no 3, p. 207 $\square 211,2017$.

12. J. C. Mazurkiewicz, S. A. Bingham, S. Runswick, et B. C. N. Ang, «Inhibition of the urease reaction by boric acid », Ann. Clin. Biochem., vol. 30, no 2, p. $215 \square 216,1993$.

13. O. Chenillot, «CRP, haptoglobine, orosomucoïde: variations biologiques et valeurs de références, relation entre $\mathrm{CRP}$ et risque cardiovasculaire ", $\mathrm{PhD}$ Thesis, UHPUniversité Henri Poincaré, 2000.

14. F. J. He, Y. Ma, N. R. Campbell, G. A. MacGregor, M. E. Cogswell, et N. R. Cook, «Formulas to estimate dietary sodium intake from spot urine alter sodium-mortality relationship », Hypertension, vol. 74, no 3, p. 572 $\square 580,2019$. 
15. T. Kawasaki, K. Itoh, K. Uezono, et H. Sasaki, « A simple method for estimating $24 \mathrm{~h}$ urinary sodium and potassium excretion from second morning voiding urine specimen in adults », Clin. Exp. Pharmacol. Physiol., vol. 20, no 1, p. 7ロ14, 1993.

16. M. Tlili, M. Landolsi, M. S. Jarrar, S. Khelifi, N. Naouar, et S.-E. Ghannouchi, «Anthropometric Characteristics of Tunisian Population in Comparison to the World Caractéristiques anthropométriques de la population tunisienne par rapport au monde », Tunis. Med., vol. 98, no 05, p. 413 $\square 419,2020$.

17. A. R. Frisancho, Anthropometric standards for the assessment of growth and nutritional status. University of Michigan press, 1990.

18. M. J. Arroyo et al., «Thread based microfluidic platform for urinary creatinine analysis », Sens. Actuators B Chem., vol. 305, p. 127407, 2020.

19. G. Marazzi et al., «Comparison of Microlife BP A200 Plus and Omron M6 blood pressure monitors to detect atrial fibrillation in hypertensive patients », Adv. Ther., vol. 29, no 1, p. 64 $\square 70,2012$.

20. C. R. Ibm, «IBM SPSS Statistics for Windows, Version Q3 25.0 », Armonk NY IBM Corp., 2017.

21. «R: The R Project for Statistical Computing ». https://www.r-project.org/ (consulté le juin 24, 2021).

22. M. Saka, P. Türker, A. Ercan, G. Kızıltan, et M. Baş, «Is neck circumference measurement an indicator for abdominal obesity? A pilot study on Turkish Adults », Afr. Health Sci., vol. 14, no 3, p. 570 $\square 75,2014$.

23. T. E. Saaristo et al., «High prevalence of obesity, central obesity and abnormal glucose tolerance in the middle-aged Finnish population », BMC Public Health, vol. 8, no 1, p. 423, 2008.

24. B. Swanepoel, A. E. Schutte, M. Cockeran, K. Steyn, et E. Wentzel-Viljoen, « Sodium and potassium intake in South Africa: an evaluation of 24-hour urine collections in a white, black, and Indian population », J. Am. Soc. Hypertens., vol. 10, no 11, p. 829 $\square 837$, nov. 2016, doi: 10.1016/j.jash.2016.08.007.

25. S. S. Yi, C. J. Curtis, S. Y. Angell, C. A. Anderson, M. Jung, et S. M. Kansagra, "Highlighting the ratio of sodium to potassium in population-level dietary assessments: cross-sectional data from New York City, USA », Public Health Nutr., vol. 17, no 11, p. 2484 $\square 2488$, nov. 2014, doi: 10.1017/S1368980014001293.

26. L. Kloss, J. D. Meyer, L. Graeve, et W. Vetter, «Sodium intake and its reduction by food reformulation in the European Union - A review », NFS J., vol. 1, p. 9 $\square$ 19, juin 2015, doi: 10.1016/j.nfs.2015.03.001.

27. K. Trieu et al., « Sodium and potassium intakes in the Kazakhstan population estimated using 24-h urinary excretion: evidence for national action », Eur. J. Nutr., p. 1 $\square$ 10, 2020.

28. A. P. Batcagan-Abueg, J. J. Lee, P. Chan, S. A. Rebello, et M. S. V. Amarra, « Salt intakes and salt reduction initiatives in Southeast Asia: A review », Asia Pac. J. Clin. Nutr., janv. 2013, Consulté le: mars 18, 2021. [En ligne]. Disponible sur: https://search.informit.org/doi/abs/10.3316/INFORMIT.733675798840839

29. K. Ando, H. Matsui, M. Fujita, et T. Fujita, « Protective effect of dietary potassium against cardiovascular damage in salt-sensitive hypertension: possible role of its antioxidant action », Curr. Vasc. Pharmacol., vol. 8, no 1, p. 59 $\square 63,2010$.

30. M. Yousefi, H. N. Saleh, M. Yaseri, M. Jalilzadeh, et A. A. Mohammadi, "Association of consumption of excess hard water, body mass index and waist 
circumference with risk of hypertension in individuals living in hard and soft water areas », Environ. Geochem. Health, vol. 41, no 3, p. $1213 \square 1221,2019$.

31. A. Grillo, L. Salvi, P. Coruzzi, P. Salvi, et G. Parati, « Sodium intake and hypertension », Nutrients, vol. 11, no 9, p. 1970, 2019.

32. P. K. Whelton, « Sodium, potassium, blood pressure, and cardiovascular disease in humans », Curr. Hypertens. Rep., vol. 16, no 8, p. 465, 2014. 